\title{
Microstructural evolution under tempering heat treatment in AISI H13 hot-work tool steel
}

\author{
Prudente W. R. ${ }^{1}$, Jefferson Fabrício C. Lins ${ }^{1}$, Siqueira R. P. ${ }^{1}$, Priscila S. N. \\ Mendes $^{1}$, Rodrigo E. Pereira ${ }^{1}$ \\ ${ }^{1}$ Department of Metallurgical Engineering, Fluminense Federal University, Volta Redonda, RJ, Brazil.
}

\begin{abstract}
The steel studied in this work belongs to the hot working class of tool steels in its applications it is essential that the tool steel have high mechanical strength properties at high temperatures in order to avoid failure due to thermal fatigue, plastic deformation, crack propagation and wear. In high temperature applications the most desirable properties are the hot hardness (Red-Hardness), tempering resistance and fatigue resistance. To meet these requirement alloying elements with strong carbide formation such as $\mathrm{Cr}, \mathrm{V}$ and Mo are used. The softening resistance of these tool steels is determined by changes suffered by the alloy carbides at high temperature and due to the recovery of the martensitic structure. Thus, the final effects of heat treatment on the microstructure and mechanical properties of the AISI H13 tool steel were studied. Microstructural characterization of samples was performed with the aid of the $\mathrm{x}$-ray diffraction and scanning electron microscopy techniques.
\end{abstract}

Keywords: AISI H13, Alloy Carbides, Heat Treatment, Secondary Hardening, Tool Steel.

\section{INTRODUCTION}

Previous research on hot work tool steels has shown that softening during tempering and fatigue at high temperature is strongly linked to the microstructure and its stability at high temperatures [1]. Typical microstructures of tool steels for hot work consist of annealed martensite with high density of dislocations and alloy carbide. The softening resistance of these tool steels is determined by changes in the alloy carbides at an elevated temperature and due to the recovery of the martensitic structure.

The AISI H13 is a chromium hot-work tool steel. Its chemistry is designed to withstand the temperature, pressure, abrasion, and thermal cycling associated with various hot working operations, including plastic injection molding, die casting, forging, and extrusion. The steel has low carbon content, around $0.4 \mathrm{wt} \%$, to promote toughness. Medium chromium content, around 5 wt.\% to provide good resistance to high temperature softening, small percentage of $\mathrm{Si}$ to improve high temperature oxidation resistance, and small molybdenum and vanadium additions (about 1\%) that form stable carbides to increase resistance to erosive wear [2].

The volumetric fraction, size, morphology and distribution of the carbides have strong effects on the mechanical properties of the steel. Studies have shown that the effect of increased resistance caused by the precipitation of carbides can significantly increase the mechanical properties of the steel [3], thus the final effects of the heat treatment on the microstructure and mechanical properties of AISI H13 steel have been extensively studied.

\section{EXPERIMENTAL PROCEDURE II.1 MATERIALS}

The material used in the proposed work are samples taken from an AISI H13 tool steel ingot, supplied by Villares siderurgy, the samples have dimensions of $10 \times 10 \mathrm{~mm}$ and $25 \mathrm{~mm}$ length and their chemical composition is shown in Table 1 .

Table 1 - Chemical composition of H13 hot-work tool steel used (wt.\%).

\begin{tabular}{c|c|c|c|c|c} 
\%C & \% Si & \% Mn & \% Cr & \% Mo & $\% \mathbf{V}$ \\
\hline $\mathbf{0 , 4 0}$ & 0,50 & 0,20 & 5,20 & 1,30 & 0,80 \\
\hline
\end{tabular}

\section{II.2 METHODS}

To study the influence of tempering temperature 5 samples were austenitized at $1020^{\circ} \mathrm{C}$ for $0,5 \mathrm{~h}$ and then 4 were tempered by varying the temperature parameter. The treatments are shown in Table 2.

Table 2 - Tempering conditions for hardness evolution measurements, carbides and martensite laths analysis.

\begin{tabular}{|c|c|c|}
\hline $\begin{array}{c}\text { Tempering } \\
\text { Sample }\end{array}$ & Temperature & Time \\
\hline $\mathbf{1}$ & $500^{\circ} \mathrm{C}$ & $2 \mathrm{~h}$ \\
\hline $\mathbf{2}$ & $550^{\circ} \mathrm{C}$ & $2 \mathrm{~h}$ \\
\hline $\mathbf{3}$ & $600^{\circ} \mathrm{C}$ & $2 \mathrm{~h}$ \\
\hline $\mathbf{4}$ & $650^{\circ} \mathrm{C}$ & $2 \mathrm{~h}$ \\
\hline
\end{tabular}




\section{II.2.1 METALLOGRAPHIC PREPARATION}

The samples were grinded on the Arotec Aropol 2V equipment, with a silica carbide sandpaper sequence of 400 \#, 600, 800 \#, 1000 \#, 1200 \#, \# 1500 and 2500 \#. For the polishing of the samples, 3 and $1 \mu \mathrm{m}$ granulation diamond paste were used, and the final polishing was done with colloidal silica OPS. Finally, the etch was done with $5 \%$ nital.

\section{II.2.2 SCANNING ELECTRON MICROSCOPY (SEM)}

In this technique a beam of electrons of controlled diameter is projected on the surface of the sample to be analyzed acquiring signals caused by collisions of these electrons with the electrons of the surface of the sample.

The microstructures of the samples were observed with the aid of a microscope Zeiss EVO Scanner MA10 with LaB6 filament.

\section{II.2.3 X-RAY DIFFRACTION (DRX)}

This technique allows us to identify the crystal structure, crystallographic texture and orientation relationship between the phases. X-ray diffraction (XRD) analysis was performed using a Shimadzu Lab X XRD-600 diffractometer, using $\mathrm{Cu}-\mathrm{K} \alpha$ radiation, with a standard goniometer. A voltage of $30 \mathrm{kV}$, current of $30 \mathrm{~mA}$ was applied during a scan between $10^{\circ}$ and $85^{\circ}$ of $2 \theta$, with the step speed of $2 \theta$ equal to $0.02^{\circ}$ and a scan speed of $2 \%$ minute. The peaks were identified by comparing the experimental data and the files from the Pearson Crystal Data (PCD) using the Powder Cell program.

\section{II.2.4 HARDNESS ROCKWELL C (HRC)}

After microstructural analysis the samples were submitted to fifteen Rockwell C hardness tests with a load of $150 \mathrm{kgf}$ for $20 \mathrm{~s}$ in a Süssen - Wolpert durometer Testor HT model.

\section{RESULTS AND DISCUSSION III.1 MICROSTRUCTURAL CHARACTERIZATION}

The microstructure evolution of the steel was investigated by XRD, scanning electron microscopy (SEM) and the quantitative image analysis was carried out with the software IMAGEJ and the ASTME1245 standard.

In the as-quenched condition, the parent austenite phase transforms into martensite which is accompanied by homogeneous elastic lattice deformation and by a significant increase in dislocation density [4].

Tempering promotes a diffusion type phase transformation from a quenched martensite (B.C.T. body centered tetragonal) to a tempered martensitic structure (B.C.C. - body centered cubic). The carbides formation and growth is strongly related to tempering time and temperature. Hence, establishing a relation between tempering conditions and microstructures is of great interest [5]. The microstructure of the steel in the as quenched state is shown in Fig. 1.

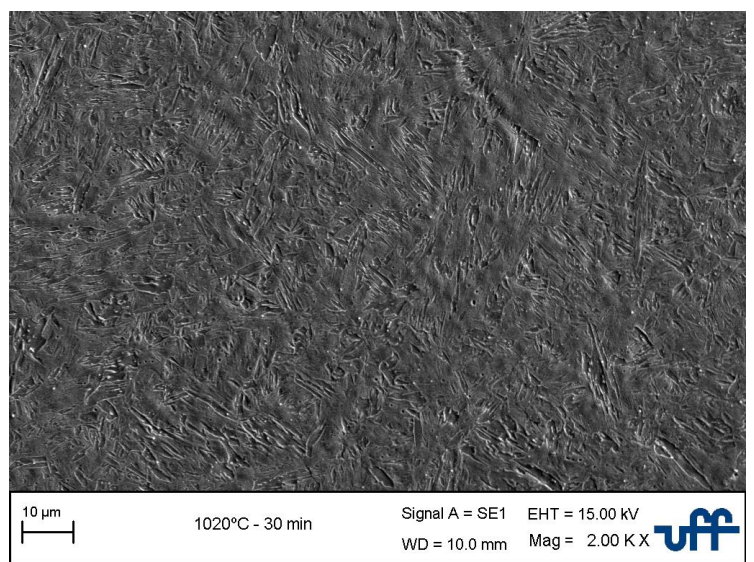

Figure 1 - AISI H13 tool steel SEM-SE micrograph of the as-quenched microstructure.

In this state the steel has a martensitic structure with high defect density, non-dissolved carbides, usually vanadium rich carbides, during austenitization (as can be observed in Fig. 3 to dissolve all carbides a high temperature is needed) and possibly some retained austenite [6].

In Fig. 2 it is possible to see the fine vanadium carbides which did not dissolve during austenitization.

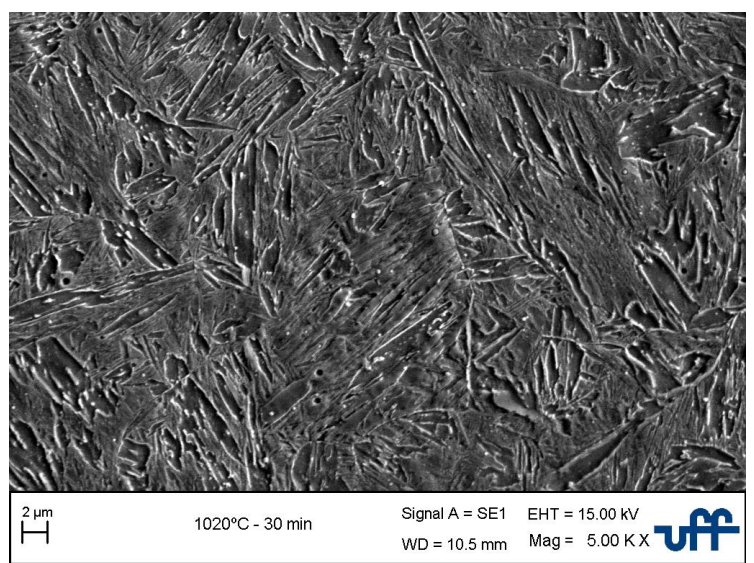

Figure 2 - AISI H13 tool steel SEM-SE micrograph of the as-quenched microstructure.

The curve shown in Fig. 3 was obtained using the Thermo-Calc software version 4.0 with the TCFe7 database. A legend with the phases found by the software is presented in table 3 . 
Table 3 - Legend of the Fig. 3 graphic.

\begin{tabular}{|c|}
\hline BCC_A2 - Ferrite $\alpha$ (CCC) \\
\hline FCC_A1 - Austenite $\gamma$ (CFC) \\
\hline M23C6 - Cr rich carbide \\
\hline M7C3 - Cr rich carbide \\
\hline HCP_A3 - Mo rich carbide \\
\hline FCC_A1 $12-$ V rich carbide \\
\hline
\end{tabular}

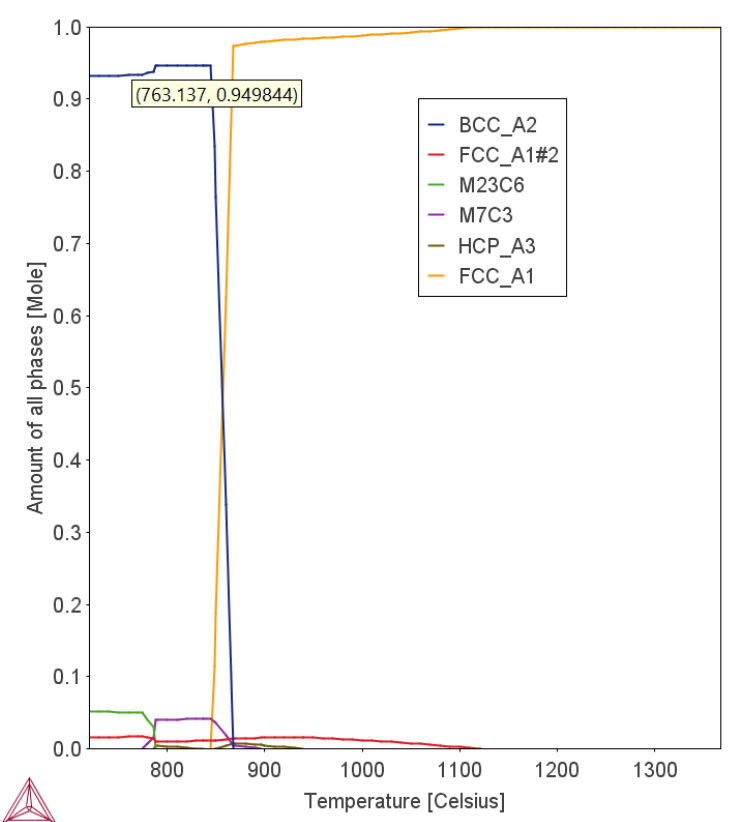

Figure 3 - It is shown the phase transformation temperature as well as the alloy carbides dissolution temperature of the AIS H13 tool steel.

In Fig. 4, 5, 6 and 7 is presented the tool steel under different tempering conditions. It is possible to note how the martensite laths increase in size and thickness with increasing temperature.

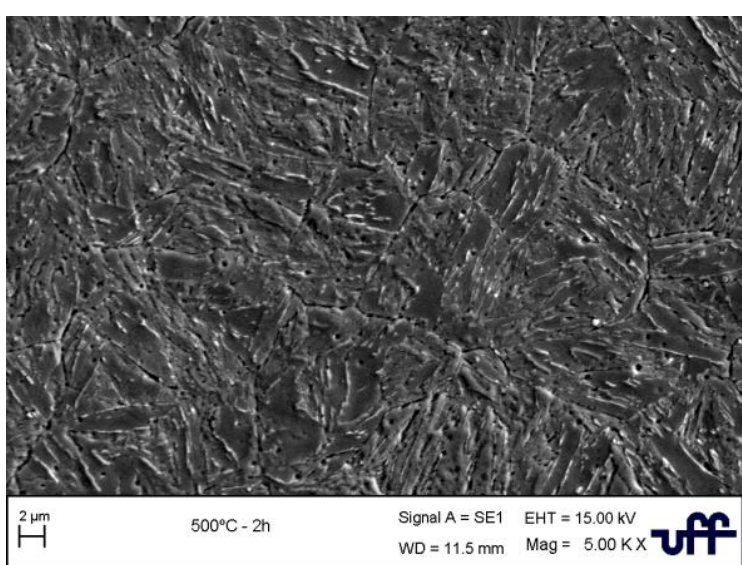

Figure 4 - SEM-SE micrograph of the AISI H13 tool steel tempered at $500^{\circ} \mathrm{C}$ for 2 hours SEM-SE micrograph.

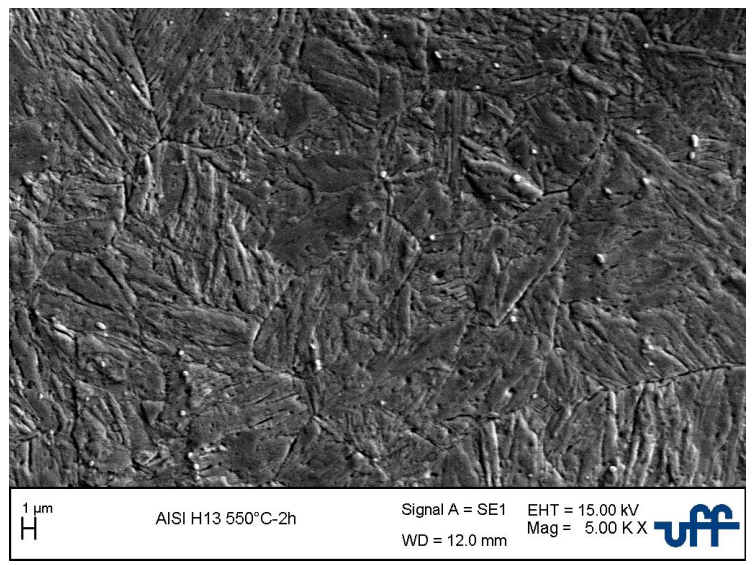

Figure 5 - SEM-SE micrograph of the AISI H13 tool steel tempered at $550^{\circ} \mathrm{C}$ for 2 hours SEM-SE micrograph.

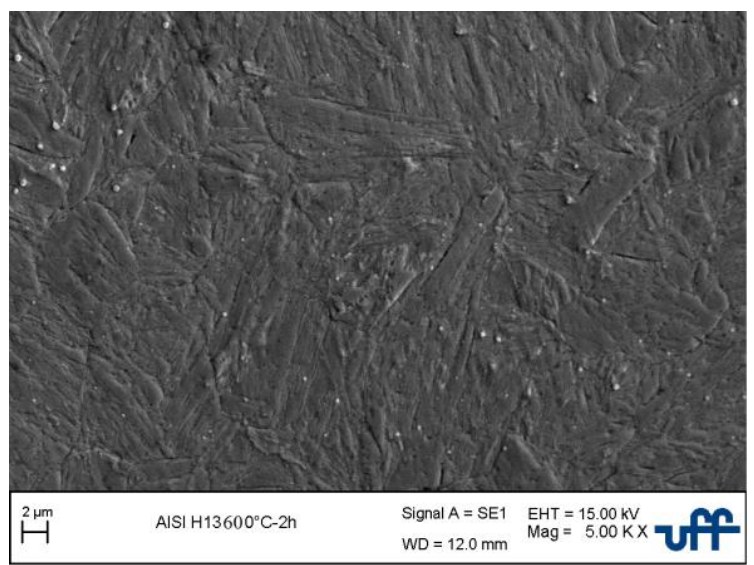

Figure 6 - SEM-SE micrograph of the AISI H13 tool steel tempered at $600^{\circ} \mathrm{C}$ for 2 hours.

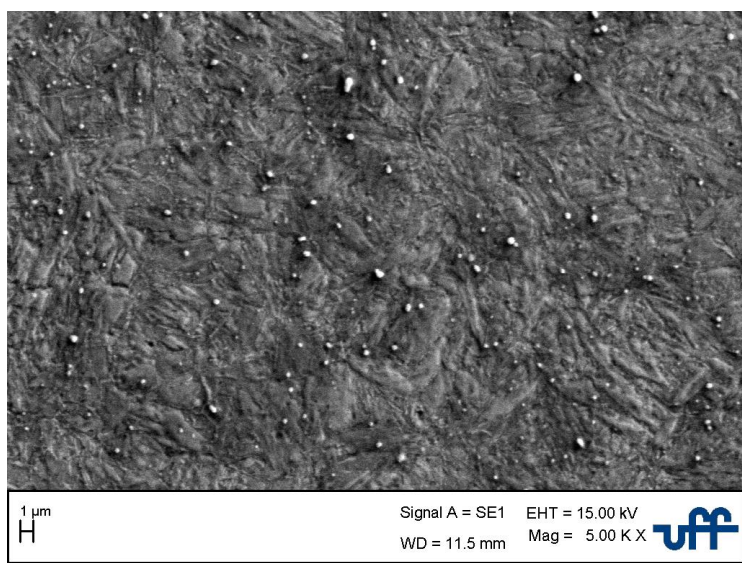

Figure 7 - SEM-SE micrograph of the AISI H13 tool steel tempered at $650^{\circ} \mathrm{C}$ for 2 hours SEM-SE micrograph

Tempering is a very complex phenomenon originating from the as-quenched microstructure of tool steels, which consists primarily of martensite with retained austenite and carbides. When hardened steel is tempered, the tetragonality of the martensite decreases and then disappears, which results in 
decrease in internal stresses. Dislocations anneal-out at $400{ }^{\circ} \mathrm{C}$. Therefore, there is decrease in the dislocation density [4]. When steel is tempered at $600^{\circ} \mathrm{C}$, the following changes in the matrix take place: internal stresses decrease; dislocations annealout; and coalescence of carbides [7].

The secondary hardening is a strengthening resulting of the replacement of coarse particles of $\mathrm{Fe} 3 \mathrm{C}$, which dissolve, by a fine dispersion of alloy carbides such as $\mathrm{VC}, \mathrm{Cr} 7 \mathrm{C} 3, \mathrm{Cr} 23 \mathrm{C} 6, \mathrm{Mo} 2 \mathrm{C}$ or Mo6C. Chromium additions result in a retardation in softening but little secondary hardening because Cr7C3 coarsens very rapidly at tempering temperatures [8]. These alloy carbides are responsible for the hardness and wear resistance in this steel

It was noticed that with the increase of the tempering temperature, more carbides were present in the microstructure, thus, 10 images at the magnification of 5000 were made and analyzed following the ASTME1245 standard, the volumetric fraction of carbides was then calculated. The mean value is presented in table 4 .

Tabela 4 - Mean value of volume fraction obtained by image analysis for the 2 hours tempered samples.

\begin{tabular}{lcccc}
\hline & Mean(\%) & S & 95\% CI & \%RA \\
\hline $\mathbf{5 0 0}^{\circ} \mathbf{C}$ & 1,4053 & 0,3049 & 0,2181 & 15,5216 \\
\hline $\mathbf{5 5 0}^{\circ} \mathrm{C}$ & 1,6105 & 0,2697 & 0,1929 & 11,9805 \\
\hline $\mathbf{6 0 0}^{\circ} \mathrm{C}$ & 2,0579 & 0,3003 & 0,2148 & 10,4365 \\
\hline $\mathbf{6 5 0}^{\circ} \mathrm{C}$ & 3,7053 & 0,4433 & 0,3171 & 8,5575 \\
\hline
\end{tabular}

In accordance with the ASTM standard it is shown in the table 4 the mean value of the volume fraction $\left(\bar{P}_{p}\right)$, the standard deviation $(\mathrm{S})$, it is also reported the $95 \%$ confidence interval for each set of fields and the relative accuracy (\%RA). It can be seen that the volume fraction highly increases with the temperature.

To analyze the martensite laths 10 images at 2000 magnification were made and analyzed through threshold and labeling, a histogram was made to understand the growth tendency of the martensite laths as shown in Fig. 8.

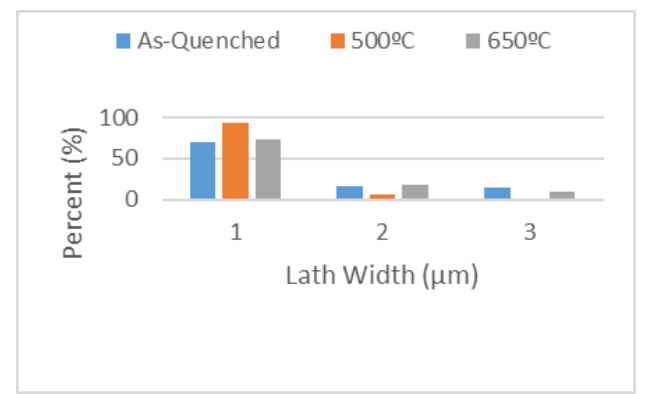

Figure 8 - Distribution of martensitic lath width
It can be seen that in all cases the majority of laths have $1 \mu \mathrm{m}$ width and as the temperature increases the width increases.

\section{III.2 X-RAY DIFFRACTION}

The X-ray diffraction test was performed in all samples, but in all tests made the only phase detected was the martensite as shown in Fig. 9, it is concluded that the volume fraction of retained austenite and carbides is low, less than $4 \%$, thus it is not detected by the test.

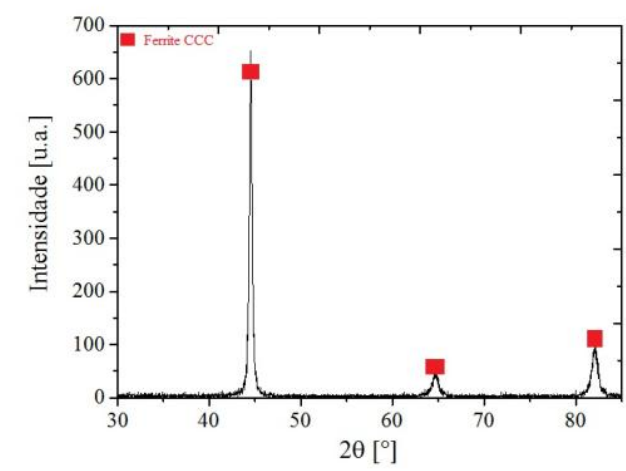

Figure 9 - X-ray diffraction of the AISI H13 Tool Steel studied.

\section{III.3 HARDNESS ROCKWELL C (HRC)}

Fifteen indentations were performed and the mean values found are shown in Fig.10.

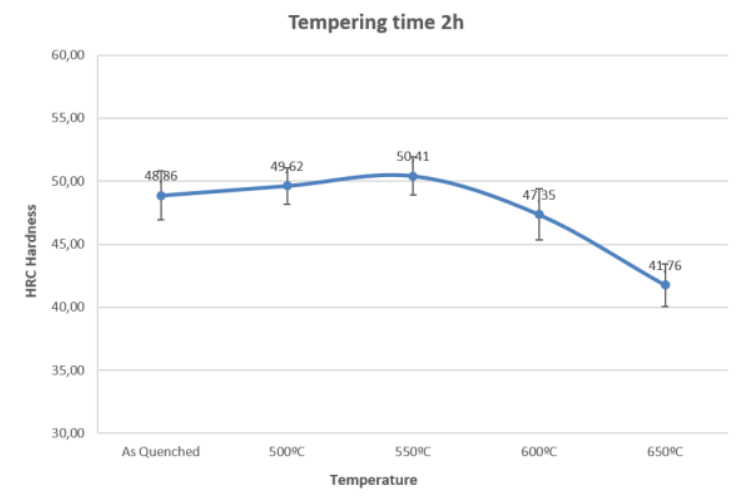

Figure 10 - Hardness evolutions during tempering for different temperatures.

The hardness is in accordance with the expected range for a material tempered for two hours. It's evident that the secondary hardening is happening because the hardness is increasing.

\section{CONCLUSION}

The microstructural evolution under tempering of the AISI H13 tool steel was investigated describing microstructural and associate hardness evolutions. The volume fraction of carbides, could not be estimated by X-ray diffraction due to its low percentage but the results indicate that 
it increases as the temperature increases. It's also reported in the literature that the size increases with time and temperature but the particle radius was not measured in this work. Regarding the martensite lath, although the effect is not so pronounced, the martensite lath width increases when the temperature increases.

\section{REFERENCES}

[1] A. Medvedeva J. Bergström, S. Gunnarsson and J. Andersson, High-temperature properties and microstructural stability of hotwork tool steels, Materials Science and Engineering A 523, 2009, 39-46.

[2] K.M. McHugh, Y. Lin, Y. Zhou, E.J. Lavernia, Influence of cooling rate on phase formation in spray-formed $\mathrm{H} 13$ tool steel, Materials Science and Engineering A 477 (2008) 50-57.

[3] Kai Miao, Yanlin He, Naqiong Zhu, Jingjing Wang, Xiaogang $\mathrm{Lu}$ and $\mathrm{Lin} \mathrm{Li}$, Coarsening of carbides during different heat treatment conditions, Journal of Alloys and Compounds 622, 2015, 513-523.

[4] R.W. Cahn and P. Hassen, Physical Metallurgy, Part 2, 3rd Ed. (North-Holland Physics Publishing, Amsterdam, 1983).

[5] Minwoo Kang, Gyujin Park, Jae-Gil Jung, Byung-Hoon Kim, Young-Kook Lee, The effects of annealing temperature and cooling rate on carbide precipitation behavior in $\mathrm{H} 13$ hot-work tool steel, Journal of Alloys and Compounds 627 (2015), 359-366.

[6] Edited by George E. Totten, in CRC Press 2006 by Taylor \& Francis Group, LLC (Ed.), Steel Heat Treatment Handbook, 651-693.

[7] R. Prasad a, S. Kumar, Study of the influence of deformation and thermal treatment on the ultrasonic behavior of steel, Journal of Materials Processing Technology 42, 1994 , 51-59.

[8] G.R. Speich and K.A. Taylor, Tempering of ferrous martensites, in Martensite, G.B. Olson and W.S. Owen, (Eds.), ASM International, Materials Park, OH, 1992, 243275. 